WellBeing International

WBI Studies Repository

$1-1995$

\title{
Vigilance, Flock Size, and Flock Geometry: Information Gathering by Western Evening Grosbeaks (Aves, Fringillidae)
}

Marc Bekoff

University of Colorado

Follow this and additional works at: https://www.wellbeingintlstudiesrepository.org/acwp_ena

Part of the Animal Studies Commons, Behavior and Ethology Commons, and the Comparative Psychology Commons

\section{Recommended Citation}

Bekoff, Marc (1995) Vigilance, Flock Size, and Flock Geometry: Information Gathering by Western Evening Grosbeaks. Ethology 99 150-161

This material is brought to you for free and open access by WellBeing International. It has been accepted for inclusion by an authorized administrator of the WBI Studies Repository. For more information, please contact wbisr-info@wellbeingintl.org.

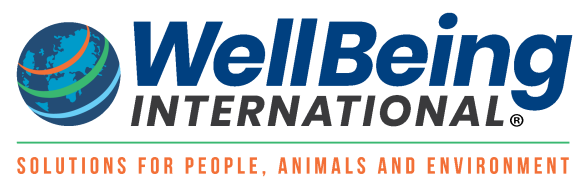


Bekoff, Marc (1995) Vigilance, Flock Size, and Flock Geometry: Information Gathering by Western Evening Grosbeaks. Ethology 99 150-161

\title{
Vigilance, Flock Size, and Flock Geometry:
}

\section{Information Gathering by Western Evening Grosbeaks \\ (Aves, Fringillidae)}

\author{
MARC BEKOFF \\ Department of Environmental, Population, and Organismic Biology \\ University of Colorado, Boulder
}

\begin{abstract}
Vigilance (scanning) and other behavior patterns were studied in free-ranging Evening Grosbeaks (Coccothraustes vespertinus) at feeders to assess how flock size and flock geometry influenced the behavior of individual birds. The present results indicate that the way in which individual grosbeaks are positioned with respect to one another effects many aspects of their behavior, especially when a flock contains four or more birds. Birds in a linear array who have difficulty seeing one another, when compared to individuals organized in a circle who can easily see one another, are (1) more vigilant, (2) change their head and body positions more often, (3) react to changes in group size more slowly, (4) show less coordination in head movements, and (5) show more variability in all measures. These differences in behavior can be explained from a cognitive ethological perspective that favors intentional or representational explanations. Specifically, the data suggest that individual grosbeaks, when scanning and moving about, are visually monitoring the flock in which they are feeding and gathering information about a number of variables including flock size, what others are doing, where others are, which individuals are present, phenotypic features of flock members, food resources, or the location of potential predators. Individuals likely use visual records of the behavior and perhaps the phenotypic features of others, and this information influences various aspects of their behavior.

Corresponding author:
\end{abstract}

Marc Bekoff

Department of Environmental, Population, and Organismic Biology

University of Colorado

Boulder

CO 80309-0334

USA. 


\section{Introduction}

Vigilance or scanning patterns displayed by individuals and groups are usually studied in the context of antipredator behavior in different habitats or conditions where resources vary. However, it is unlikely that vigilance serves a single function (ALLEN \& BEKOFF 1994a). Being vigilant improves the chances of detecting possible predators, but individuals can also gain information about the activities, location, age, sex, and size of other group members, or about resources including the type food and quantity of available food. LAZARUS (1990) notes that researchers frequently assume scanning behavior is vigilance, and have then sought its function.

A major question in the study of vigilance is, How does the scanning behavior of individuals vary in groups of different sizes? Many studies have shown that there is a negative relationship between group size and rates of scanning by individuals (ELGAR 1989; LIMA 1990, 1994; LIMA \& DILL 1990; CARO 1994). Less-well-demonstrated is the positive relationship between group size and the probability of predator detection (ELGAR 1989; LIMA 1990, 1994; LIMA \& DILL 1990). These relationships emerge probably because there are more eyes and perhaps other sense organs that can be used to detect predators (ELGAR 1989; LIMA 1990; LIMA \& DILL 1990). Another, and perhaps more important question is, Why is the relationship between group size and scanning rates sometimes not found? These data should not be viewed as noise, but rather they can be used to explain the unique behavior and ecology of a species (e.g., CATTERALL et al. 1992) and to inform and motivate new research as well as reanalyses of old data. Further, the pooling of data from individuals in flocks of the same size but organized in different geometric arrays can mask interesting differences among birds in flocks of varying geometries. These differences can also inform cognitive inquiries into scanning behavior.

The main question of interest here is, How do group size and geometric distribution of individuals in a group influence individual vigilance and other patterns of behavior? It is suggested that variables such as the geometric relationships among group members that influence their visibility by other group members--their arrangement in a circle, a triangle, or in a straight line, for example--might influence scanning rates and other patterns of behavior. While some authors write about visual obstructions, they do not consider the actual geometry of the group (METCALFE 1984a,b; ELGAR 1989; QUENETTE 1990). For example, ELGAR writes about how visual obstructions might influence vigilance and risk of predation, but does not directly refer to geometry as a variable influencing scanning for predators. Likewise, in his review of vigilance in mammals, QUENETTE (1990) notes that visual obstructions affect vigilance because they influence what information is received from the environment. ELGAR et al. (1984) also review literature showing that, in general, scanning rates in small passerines do not decrease significantly with flocks larger than eight or nine birds. They conclude that it is possible that sparrows simply cannot estimate the number of birds in larger flocks. Certainly, it is possible that birds and other animals cannot estimate the number of birds in flocks that are organized in a way such that visual inspection is difficult or impossible. Attention to what an individual might know about itself and others would be useful here by suggesting possibilities for empirical study and the generation of predictive models. Answers to the question "How does the geometric distribution of individuals, whether they are organized in circular or linear arrays, influence individual vigilance?" will likely provide insights into animal cognition because information gathering can provide evidence of cognitive processes (ALLEN \& HAUSER 1993). 
This study primarily concerns information about other flock members that individual Evening Grosbeaks (Coccothraustes vespertinus) might acquire while visually scanning. I hypothesized differences in vigilance and other behavior patterns shown by animals feeding in various geometric arrays would be explained by the differences in the ability of individuals to gain information about what other flock members are doing. I predicted that individuals organized in lines where visual monitoring is difficult, when compared to individuals organized in circles where visual monitoring is easy, would (1) be more vigilant, (2) change their positions more often, (3) show greater delays to changes in group size, and (4) show less coordination in head movements. Relationships among these variables have not previously been studied. Furthermore, I predicted that some patterns of scanning would be explained by what is known about how individual grosbeaks assess dominance relationships with other grosbeaks in their flocks (see below and BEKOFF\& SCOTT 1989). Evening Grosbeaks often vocalize when in groups (BEKOFF\& SCOTT 1989), and although it is possible that auditory cues are important in influencing the behavior of flock members (e.g., SULLIVAN 1984), this was not considered here. It also is unclear if birds actually see (or hear) what humans think they see (or hear; for detailed discussions concerning vision, see KEELING \& DUNCAN [1989] and various chapters in ZEIGLER\& BISCHOF [1993]). LIMA (1990) concluded that little is known about the perceptions of the animals being studied and that many models of vigilance reflect the perceptions of the modelers themselves.

\section{Methods}

Free-ranging Evening Grosbeaks were observed and filmed about $3 \mathrm{~km}$ west of Boulder, Colorado (elevation approximately $1900 \mathrm{~m}$ ) from June 1986-July 1992 while they fed on square platform feeders $(60 \mathrm{~cm} \times 60 \mathrm{~cm})$ or on a narrow rail $(14 \mathrm{~cm} \times 180 \mathrm{~cm})$. Films were mostly taken from mid-May through early-October and analyzed frame-by-frame. Observations and films were made through clear windows on a horizontal plane at "eye level" and also from 5 to $7 \mathrm{~m}$ above the birds in order to gather information about flock size and flock geometry. The presence of observers did not seem to influence the behavior of birds after observers remained still. To control as much as possible for confounding influences on scanning patterns (ELGAR 1989; LIMA 1990, 1994; LIMA \& DILL 1991), from year-to-year the same amount and mix of seeds were provided daily at about 0600 h (Rocky Mountain Best Bird Seed ${ }^{\text {\&tm; }}$ white proso millet, block sunflower, and canary grass seed) so that handling time did not differ, distance to cover was the same, and potential predators did not differ (mainly domestic cats, Felis domesticus, but also and rarely black-billed magpies, Pica pica, and American crows, Corvus brachyrhynchos). The area immediately surrounding the feeders and the rail was open; there were no trees that could obscure the presence of potential predators. The high turnover in marked birds (BEKOFF \& SCOTT 1989) suggested it is unlikely that familiarity among individuals influenced patterns of vigilance (see below).

Each data point represents a flock of a given size, and it was assumed that because of the high mobility of grosbeaks within and between filming sessions, each data point was made up of mostly different individuals and were independent of one another. A circular array was one where each bird in the flock was oriented so that it had a clear line of sight to all other birds, and a linear array was a noncircular array in which each bird was oriented so that it had a clear line of 
sight to at most two other birds; a triangle was considered to be a circular array. Data that did not fit into either of these categories were discarded for the present analysis. Circular arrays were only observed on the feeders, whereas linear arrays were observed on feeders and rails. Single birds and flocks of two birds were included in the present analysis but were not classified as being in circles or lines for obvious reasons. Individuals standing on a feeding platform or along a narrow rail were considered to be members of a single flock when the distance between them was less than or equal to about $0.5 \mathrm{~m}$. To be included in the present analysis, flocks had to be stable with respect to membership for at least $15 \mathrm{~s}$. The only visual obstructions were the birds themselves. Standard measures of "scanning" ("head up") and "not scanning" ("head down") were used (LIMA 1990) and standard statistical analyses were performed using SPSS. For the point-serial correlation analyses (WELKOWITZ et al. 1976:184-186), in which the coordination of head movements among flock members was determined, the dichotomous variable was head position and the continuous variable was group size (following LIPETZ \& BEKOFF 1982:21ff). "Less coordination" (smaller point-serial correlation) means that there were fewer instances when all the birds in linear flocks of a given size were scanning or not scanning at the same time when compared to birds in a circular flock of the same size. Differences in the point-serial correlations were analyzed using the method ( $\mathrm{t}_{\mathrm{s}}$ statistic) for testing the homogeneity among two or more correlation coefficients suggested by SOKAL \& ROHLF (1981:588-589). In the analysis of movements of an individual's head and body (Figure 2), an individual's head and body could move together or separately. Degrees of head or body movements were not scored. Extremely small movements of the body alone were not scored, whereas small head movements, the results of which were most likely a change in the visual field, were counted. Behavior patterns shown in response to a change in group size included moving into the unoccupied space where a bird had been, changing patterns of scanning, or acknowledging the arrival of another bird by moving toward and socially interacting with--e.g., pecking at, sidling into, or displaying at the newcomer (BEKOFF \& SCOTT 1989). Focal individuals in circular or linear arrays were observed to see how long it took for them to react to the arrival or departure of a nonadjacent bird, the result of which was a change in group size, and not merely the arrival or departure of an individual. When organized in a linear array, there were usually 2-3 individuals between focal birds and departing or arriving birds.

\section{Results}

Individual grosbeaks arranged in linear arrays of three or more birds on rails and on feeders on average (1) are more vigilant (Figure 1), (2) change their head and body positions more often to orient toward other flock members (Figure 2), (3) react to changes in group size more slowly (Figure 3), and (4) show more variability on all measures (based on an analysis of coefficients of variation). Birds in linear groups of four or more individuals also show less coordination in head movements (Figure 4), although the differences in the point-serial correlation coefficients between same sized circular and linear flocks are not statistically significant (in all comparisons, $\left.\mathrm{t}_{\mathrm{s}}<1.96, \mathrm{p}>0.05\right)$. Differences between the behavior of individuals in linear arrays on feeders and in linear arrays on rails were not studied, thus it is not known whether the difference in seed density on rails and feeders influenced scanning and vigilance (a possibility suggested by Mark Elgar personal communication).

PLACE FIGURES 1 - 4 HERE 
In the analyses of the mean proportion of time spent scanning (Figure 1), coefficient of variations were greater for birds in linear arrays for group sizes of 3-10. For circular and linear groups of 3 individuals there was no significant difference in the mean proportion of time spent scanning ( $\mathrm{F}$ $=1.84, \mathrm{p}=0.18$, $\mathrm{df}=1,366$ ), and for all comparisons for groups of 4 of more birds individuals in linear arrays spent a higher mean proportion of time scanning $(\mathrm{F}>13.42, \mathrm{p}<0.0003)$. Furthermore, there were no significant differences among the most disparate correlation coefficients $(\mathrm{t}<1.96, \mathrm{p}>0.05)$. Mean interscan intervals were about the same for individuals in circular $(X=2.9 \mathrm{~s}, \mathrm{SD}=2.7)$ and linear $(X=2.6 \mathrm{~s}, \mathrm{SD}=2.1 ; \mathrm{F}=1.19, \mathrm{p}>0.05, \mathrm{df}=1,560)$ flocks of the same size.

Linear regression analyses showed that the relationship between the mean proportion of time spent scanning by individuals and the mean number of changes in body and head position were significantly and negatively related to group size when birds were organized in circles $(\mathrm{X}$ proportion of time spent scanning by individuals: $\mathrm{F}=10.83$, $\mathrm{p}<0.02$; mean number of changes in body and head position: $\mathrm{F}=6.49, \mathrm{p}<0.05)$, but neither of these measures was significantly related to group size when birds were organized in lines (X proportion of time spent scanning by individuals: $\mathrm{F}=1.75, \mathrm{p}=0.24$; mean number of changes in body and head position: $\mathrm{F}=3.60, \mathrm{p}$ $=0.12$ ). In all comparisons for group sizes of 3-6, coefficient of variations were greater for birds in linear arrays. For circular and linear groups of 3 individuals there was no significant difference in the mean number of changes in body and head position $(\mathrm{F}=0.65, \mathrm{p}=0.42$, $\mathrm{df}=1,117)$, and for all comparisons for groups of 4 of more birds individuals in linear arrays changed their positions significantly more than did birds in circular arrays $(F>7.98, p<0.005)$. For both measures, adjusted coefficients of determination $\left(\mathrm{r}^{2}\right)$ were higher for birds organized in circles $(\mathrm{X}$ proportion of time spent scanning by individuals: $\mathrm{r}^{2}=0.62$; mean number of changes in body and head position: $r^{2}=0.47$ ) than for birds organized in a linear array (X proportion of time spent scanning by individuals: $\mathrm{r}^{2}=0.11$; mean number of changes in body and head position: $\mathrm{r}^{2}=$ 0.30), indicating that a larger percentage of variation in each measure was explained by group size.

With respect to the delay shown in response to a change in group size, regression analyses showed a positive and significant relationship between mean delay and group size for birds organized in lines $(\mathrm{F}=20.45, \mathrm{p}=0.006)$ but not for birds in circles $(\mathrm{F}=1.03, \mathrm{p}=0.36)$ Not only did birds organized in lines show a longer and more significant delay, but adjusted $r^{2}$ values indicated that $76 \%$ of the variation in mean delay was accounted for by group size when birds were in lines, whereas only $1 \%$ of the variation in mean delay was accounted for by group size when birds were in circles. In all comparisons for group sizes of 3-10, coefficient of variations were greater for birds in linear arrays. For circular and linear groups of 3 individuals there was no significant difference in the delays in response to changes in group size $(\mathrm{F}=1.73, \mathrm{p}=0.19$, df $=1,397$ ), and for all comparisons for groups of 4 of more birds individuals in linear arrays showed significantly longer delay than did birds in circular arrays $(F>37.01, p<0.0009)$.

Grosbeaks in this study area are not exposed to heavy predation. Only three instances of successful predation by two domestic cats were observed (see also DUNN \& TESSAGLIA 1994) and aerial predators were never observed to attempt to capture either young or adult grosbeaks. 


\section{Discussion}

\section{Visual Monitoring and Social Behavior: Why Are Individual Grosbeaks Busy and Nosy?}

The present results for Evening Grosbeaks show clearly and for the first time that flock geometry is an important variable that can influence patterns of scanning and other aspects of behavior. Each finding alone may not provide convincing evidence for the suggestion that birds are monitoring visually the behavior of other flock members. However, the differences in behavior and the differences in the amount of variation in behavior that were accounted for solely by group size for comparisons of grosbeaks organized in circular arrays, when compared to birds organized in linear arrays, when taken together, can be explained by the possibility that an individual grosbeak is attempting to obtain information about a number of environmental variables, via visual monitoring. The variables include (1) flock size, (2) what others are are doing, (3) where other flock members are, (4) which individuals are present, (5) specific phenotypic features that are related to age, sex, and size, (6) the availability and nature of food resources, or $(7)$ the presence of potential predators. These data are related to questions concerned with why birds might attempt to represent their flock to themselves. ELGAR et al (1984) and METCALFE (1984a,b) hypothesize that some birds do attempt to inspect visually other flock members. CARACO \& BAYHAM (1982) also report that in flock-living house sparrows (Passer domesticus), nearest neighbors tend to orient themselves so as to keep one another in view. Nonetheless, as LIMA (1994) points out, changes in behavior with changes in group size do not necessarily imply that group members monitor each other's behavior.

Why might individual grosbeaks be busy and nosy? The present results suggest that visual obstructions, in this case other grosbeaks in a flock, can interfere with monitoring the behavior of other flock members. In flocks of four or more birds, individuals seem to change their behavior based on what they are able to see. When there were visual obstructions, grosbeaks not only spent more time being vigilant, but they also changed their head and body positions more often, responded to changes in group size more slowly, and showed less coordination in scanning in linear flocks (see also PULLIAM 1973; BERTRAM 1980). The high and random turnover in marked grosbeaks (BEKOFF \& SCOTT 1989) suggested that familiarity among individuals was unlikely to influence patterns of vigilance, and it is possible that the lack of familiarity with the behavior patterns of other individuals is one reason that a higher proportion of time was spent scanning by grosbeaks than has been observed in other studies of more stable flocks of birds. The high scanning rates observed in the present study might also be related to the fact that individual grosbeaks are trying to gather a lot of different types of information when scanning and moving around (see also CATTERALL et al. 1992). Evening grosbeaks are not aggressive when feeding and it has been suggested that temporary flocks of grosbeaks composed of mainly transient birds are maintained by individuals assessing relative dominance status and the likely future outcome of agonistic encounters with another individual using information from various phenotypic cues that require visual inspection (BEKOFF \& SCOTT 1989). In agreement with the data presented here, METCALFE (1984a) and REDPATH (1988) also found that obscured vision can lead to increases in vigilance (but see LIMA 1987). With respect to possible influences of group geometry on scanning, J. BERGER (personal communication) notes that in his work on group size and foraging efficiency in bighorn sheep, differences in group geometry 
might have accounted for the large variations in behavior that were thought to be primarily influenced by group size (see BERGER 1991:68-69).

More data are needed for other taxa to assess if the relationship between group size and individual scanning rates levels off or is not observed because of the inability of individuals to monitor the behavior of "too many other animals" who are also difficult to see (e.g., CATTERALL et al. 1992). Future comparative research, including developmental studies (e.g., ALBERTS 1994), should also concentrate on variables that could influence individual patterns of scanning and other behavior patterns such as those studied here. These variables include age, sex, dominance rank, food handling time, distance to cover, previous experience with predators, predator pressure, and the role of auditory cues. More controlled experiments also need to be conducted to investigate the effects of, and interactions among, flock size, flock geometry, the relative positions of individuals (e.g., KRAUSE 1994), and the classes of individuals who are in these flocks. There may be trade-offs such that although it is easier to see what other flock members are doing when birds are arranged in a specific geometric array (circles), it also is easier for potential predators to see the group or specific individuals, especially if the flock is more obvious because it is larger or noisier.

\section{Interdisciplinary Studies of Scanning, Information Gathering, and Cognition: Grosbeaks As A Test Case}

Interdisciplinary input is helpful for finding answers to questions concerning animal cognition, specifically about the notions of intentionality, content, representation, and information (KREBS 1987; ALLEN 1992, 1995; ALLEN \& HAUSER 1993; BEKOFF \& ALLEN 1992, 1995; JAMIESON \& BEKOFF 1993). Intentionality is the property of being about other things, and is a feature of mental and other representations. Information is also an intentional notion because animals process information about their worlds. A great challenge for those who study cognitive ethology is to learn more about how information is processed and represented, how individuals form representations, how information storage is related to sensory abilities, how what is represented influences future behavior, and the evolution of cognition and intentionality (e.g., CHENEY \& SEYFARTH 1990, 1992; GRIFFIN 1992; ALLEN \& HAUSER 1993; REAL 1993; ALLEN \& BEKOFF 1994b; BERNAYS\& WCISLO 1994).

With respect to the present study, representational accounts of scanning patterns are useful for explaining at least some of the behavior of grosbeaks organized in flocks of different sizes and of different geometric arrays. The hypothesis that birds make assessments of group size is not incommensurate with known abilities. Individuals of many species learn and remember the location of numerous food caches and show other types of spatial memory that suggest the use of cognitive maps (SPEAKMAN 1987; BINGMAN 1993). Some birds also display category and concept formation (PEPPERBERG 1990, 1994), perceive pictures as representations of objects (WATANABE et al. 1993), discriminate between stimulus arrays on the basis of the number of items they contain, and can form an internal representation of a moving stimulus and extrapolate the movement of a stimulus that is no longer visible (EMMERTON\& DELIUS 1993). Also, although more studies are needed, there are data that show that some pigeons can store precise information of up to 7 items in a set (EMMERTON \& DELIUS 1993). Perhaps this limit influences patterns of vigilance for groups of about this size or larger. Recall ELGAR et al.'s 
(1984) observation that scanning rates in small passerines do not decrease significantly with flocks larger than eight or nine birds because of the possibility that they cannot estimate the number of birds in larger flocks. Whether or not birds are subitizing (rapidly assigning a numerical tag to small quantities of items in a simultaneously presented array) or actually counting (discriminating the absolute number of a set of items on an ordinal scale) the effect of the number of other individuals in a flock awaits empirical studies (for discussions of subitizing and counting see DAVIS\& PéRUSSE 1988 and BOYSEN \& CAPALDI 1993). D. CRAIG (personal communication) also notes that there might be diminishing returns in that, for example, 22 eyes are not more effective than 16 eyes.

There are many good reasons for advocating cognitive ethological analyses and intentional or representational explanations of animal behavior. As WATANABE et al. (1993:372) note with respect to their research on concept discrimination in pigeons: "The question is not whether pigeons have been proved beyond a reasonable doubt to possess and use concepts, but whether it has proved fruitful to ask whether they do." McCLEAN \& RHODES (1991) also recognize the utility of cognitive models and intentional explanations in studies of enemy recognition in birds (see also CHENEY \& SEYFARTH 1990, 1992; RISTAU 1991). Previously, vigilance behavior was explained by appealing to flock size as a stimulus condition. In the present study, questions about the interaction of flock size and flock geometry would not have been pursued without taking into account questions about representation. Furthermore, consideration of the possibility of the importance of visual representations for group-living grosbeaks motivated study of other aspects of their behavior including rates of body and head movements, delays in response to changes in group size, and patterns of coordination of head movements which could then be related to the social behavior and ecology of these birds. When the results of all of these analyses were combined, a stronger case could be made for the utility of representational accounts.

When choosing among competing, but necessarily mutually exclusive explanations it is important to ask questions such as is the explanation doing the work that we want it to do--where does it lead heuristically, how much variation does it account for, and what is its predictive power? Different sorts of explanations may apply to different situations, and there seems to be little justification for advocating one type of explanation to the exclusion of others for all (or even many) of the diverse patterns of behavior shown by different animals (see also MCCLEAN \& RHODES 1991; BEKOFF 1995). For example, the results of the present study, that flock geometry influences various patterns of behavior, are more simply explained in terms of the representational needs or information-gathering goals of grosbeaks than by an attempt to account for the effects of group geometry in terms of (numerous) stimulus-response contingencies (e.g., birds are somehow conditioned [or innately predisposed] to produce certain behavioral patterns in response to group geometry). For in this case it is difficult to conceive that an individual grosbeak could have received explicit conditioning about the factors that influence when and how it should scan or move its head and body. Similarly, SPEAKMAN (1987) found that theories of spatial learning in birds (and other animals) that postulate mental or cognitive maps provide better predictions of behavior than theories that reject the idea of internal constructs. The applicability of representational information gathering approaches to the study of different behavior patterns in a wider array of species awaits further empirical study.

\section{Acknowledgements}


I thank Colin ALLEN, Kim STERELNY, Dale JAMIESON, Larry SHAPIRO, Eric SAIDEL, David ROSENTHAL, Daniel BLUMSTEIN, Ruth MILLIKAN, Susan TOWNSEND, John LAZARUS, Joel BERGER, Cecelia HEYES, Daniel DENNETT, Gordon BURGHARDT, Steve LIMA, and Thomas VALONE for discussing many of these general and specific issues with me over the past few years. Colin ALLEN, Steve LIMA, Carolyn RISTAU, Deborah BEKOFF, Elisabeth AMMOM, David CRAIG, Susan TOWNSEND, Mark ELGAR, Jane BROCKMANN, and an anonymous reviewer provided comments on an ancestral version of this paper, and Michael C. GRANT did the statistical analyses. Funds that helped to support this research came from The National Geographic Society, The Whitehall Foundation, The American Philosophical Society, and The University of Colorado (two grants-in-aid and two sabbatical leaves).

\section{Literature Cited}

ALBERTS, S. C. 1994: Vigilance in young baboons: effects of habitat, age, sex and maternal rank on glance rate. Anim. Behav. 47, 749-755.

ALLEN, C. 1992: Mental content and evolutionary explanation. Biol. Philos. 7, 1-12.

-- -- 1995: Intentionality: Natural and artificial. In: Comparative Approaches to Cognitive Science. (MEYER, J.-A. \& ROITBLAT, H., eds.) MIT Press, Cambridge, Massachusetts, in press.

-- -- \& BEKOFF, M. 1994a: Function, natural design, and animal behavior: Philosophical and ethological considerations. Persp. Ethol. 12, in press.

-- -- \& -- -- 1994b: Intentionality, social play, and definition. Bio. and Phil. 9, 63-74.

-- -- \& HAUSER, M. 1993: Communication and cognition: Is information the connection? Phil. Sci. Assoc. 2, 81-91.

BEKOFF, M. 1995 Cognitive ethology and the explanation of nonhuman animal behavior. In: Comparative Approaches to Cognitive Science. (MEYER, J.-A.\& ROITBLAT, H., eds.) MIT Press, Cambridge, Massachusetts, in press.

-- -- \& ALLEN, C. 1992: Intentional icons: towards an evolutionary cognitive ethology. Ethology 91, 1-16.

-- -- \& -- -- 1995: Cognitive ethology: Slayers, skeptics, and proponents. In: Anthropomorphism, Anecdote, and Animals: The Emperor's New Clothes? (MITCHELL, R. W., THOMPSON, N. \& MILES, L., eds.), University of Nebraska Press, Lincoln, in press.

-- -- \& SCOTT, A. C. 1989: Aggression, dominance, and social organization in evening grosbeaks. Ethology 83, 177-194.

BERGER, J. 1991: Pregnancy incentives, predation constraints and habitat shifts: Experimental and field evidence for wild bighorn sheep. Anim. Behav. 41, 61- 77. 
BERNAYS, E. A. \& WCISLO, W. T. 1994: Sensory capabilities, information processing, and resource specialization. Q. Rev. Biol., 69, 187-204.

BERTRAM, B. C. R. 1980: Vigilance and group size in ostriches. Anim. Behav. 28. 278- 286.

BINGMAN, V. P. 1993: Vision, cognition, and the avian hippocampus. In:Vision, Brain, and Behavior in Birds. (ZEIGLER, H. P. \& BISCHOF, \& H.-J., eds.) MIT Press, Cambridge, Massachusetts, pp. 391-408.

BOYSEN, S. T. \& CAPALDI, E. J. (ed) 1993: The Development of Numerical Competence: Animal and Human Models. Lawrence Erlbaum, Hillsdale, New Jersey.

CARACO, T. \& BAYHAM, M. C. 1982: Some geometric aspects of house sparrow flocks. Anim. Behav. 30, 990-996.

CARO, T. M. 1994: Cheetahs of the Serengeti: Group living in an asocial species. Univ. of Chicago Press, Chicago.

CATTERALL. C. P., ELGAR, M. A. \& KIKKAWA, J. 1992: Vigilance does not covary with group size in an island population of silvereyes (Zosterops lateralis). Behav. Ecol. 3, 207-210.

CHENEY, D. L. \& SEYFARTH, R. M. 1990: How Monkeys See the World: Inside the Mind of another species. Univ. Chicago Press, Chicago.

-- -- \& -- -- 1992: Précis of How monkeys see the world: Inside the mind of another species. Behav. Brain Sci., 15, 135-182.

DAVIS, H. \& PéRUSSE, R. 1988: Numerical competence in animals: Definitional issues, current evidence, and a new research agenda. Behav. Brain Sci. 11, 561-615.

DUNN, E. H. \& TESSAGLIA, D. L. 1994: Predation of birds at feeders in winter. J Field Ornith. $65,8-16$.

ELGAR, M. A. 1989: Predator vigilance and group size in mammals and birds: A critical review of the empirical evidence. Biol. Rev. 64, 13-33.

-- --, BURREN, P. J. \& POSEN, M. 1984: Vigilance and perception of flock size in foraging house sparrows Passer domesticus L. Behaviour 90, 215-223.

EMMERTON, J. \& DELIUS, J. D. 1993: Beyond sensation. Visual cognition in pigeons. In: Vision, Brain, and Behavior in Birds. (ZEIGLER, H. P. \& BISCHOF, \& H.-J., eds.) MIT Press, Cambridge, Massachusetts, pp. 377-390.

GRIFFIN, D. R. 1992: Animal Minds. Univ. Chicago Press, Chicago. 
JAMIESON, D. \& BEKOFF, M. (1993): On aims and methods of cognitive ethology. Phil. Sci. Assoc., 2, 110-124.

KEELING, L. J. \& DUNCAN, I. J. H. 1989: Inter-individual distances and orientation in laying hens housed in groups of three in two different-sized enclosures. Appl. Anim. Behav. Sci. 24, 325-342.

KRAUSE, J. 1994: Differential fitness returns in relation to spatial position in groups. Biol. Rev. 69, 187-206.

KREBS, J. R. 1987: Foraging, learning and information. In: Animal Societies: Theories and Facts. (ITô, Y., BROWN, J. L., \& KIKKAWA, J., eds.) Japan Sci. Soc. Press, Tokyo, pp. 267284

LAZARUS, J. 1990: Looking for trouble. New Sci. 125, 62-65.

LIMA, S. L. 1987: Distance to cover, visual obstructions, and vigilance in house sparrows. Behaviour 102, 231-238.

-- -- 1990: The influence of models on the interpretation of vigilance. In: Interpretation and Explanation in the Study of Animal Behavior: Vol. II, Explanation, Evolution, and Adaptation. (BEKOFF, M. \& JAMIESON, D., eds.) Westview Press, Boulder, Colorado, pp. 246-267.

-- -- 1994: Back to the basics of anti-predatory vigilance. The group size effect. Anim. Behav. in press.

-- -- \& DILL, L. M. 1990: Behavioral decisions made under the risk of predation: A review and prospectus: Can. J. Zool. 68, 619-640.

LIPETZ, V. E. \& BEKOFF, M. 1982: Group size and vigilance in pronghorns. Z. Tierpsychol. $58,203-216$.

MCCLEAN, I. G. \& RHODES, G. 1991: Enemy recognition and response in birds. In: Current Ornithology, Volume 8. (POWER, D. M., ed.) Plenum Press, New York, pp. 173-211.

METCALFE, N. B. 1984a: The effects of habitat on the vigilance of shorebirds: Is visibility important? Anim. Behav. 32, 981-985.

-- -- 1984b: The effects of mixed-species flocking on the vigilance of shorebirds: Who do they trust? Anim. Behav. 32, 986-993.

PEPPERBERG, I. 1990: Some cognitive capacities of an African grey parrot (Psittacus erithacus). Adv. Study Behav. 19, 357-409.

-- -- 1994 Numerical competence in an African grey parrot (Psittacus erithacus). J. Comp. Psychol. 108, 36-44. 
PULLIAM, H. R. 1973: On the advantages of flocking. J. Theoret. Biol. 38, 419-422.

QUENETTE, P.-Y. 1990: Functions of vigilance behaviour in mammals: A review. Acta Oecologica 11: 801-818.

REDPATH, S. 1988: Vigilance levels in preening Dunlin Calidris alpina. Ibis 130, 555- 557.

REAL, L. A. 1993: Toward a cognitive ecology. Trends Ecol. Evol. 8, 413-417.

RISTAU, C. 1991: Aspects of the cognitive ethology of an injury-feigning bird, the piping plover. In: Cognitive Ethology: The Minds of Other Animals. Essays in Honor of Donald R. Griffin. (RISTAU, C., ed.) Lawrence Erlbaum, Hillsdale, New Jersey, pp. 91-126.

SOKAL, R. R. \& ROHLF, F. J. 1981: Biometry. W. H. Freeman, San Francisco.

SPEAKMAN, A. 1987: Place cells in the brain: Evidence for a cognitive map. Sci. Prog. Oxford 71, 511-530.

SULLIVAN, K. A. 1984: Information exploitation by downy woodpeckers in mixed-species flocks. Behaviour, 91, 294-311.

TINBERGEN, N. 1963: On aims and methods of ethology. Z. Tierpsychol. 20, 410-429.

WATANABE, S., LEA, S. E. G. \& DITTRICH, W. H. 1993: What can we learn from experiments on pigeon concept discrimination? In:Vision, Brain, and Behavior in Birds. (ZEIGLER, H. P. \& BISCHOF, \& H.-J., eds.) MIT Press, Cambridge, Massachusetts, pp. 351376.

WELKOWITZ, J., EWEN, R. B. \& COHEN, J. 1976: Introductory Statistics for the Behavioral Sciences. Second edition. Academic Press, New York

ZEIGLER, H. P. \& BISCHOF, H.-J. (eds) 1993: Vision, Brain, and Behavior in Birds. MIT Press, Cambridge, Massachusetts.

\section{Figure legends:}

Fig. 1: The mean (+/- SD) proportion of time spent scanning by individual grosbeaks as a function of group size and group geometry. Sample sizes for birds in circles for the listed group sizes were (left to right) 217, 253, 195, 203, 225, 216, and 163. For birds in lines sample sizes were $217,253,173,114,101,88$, and 72 .

Fig. 2: The mean (+/- SD) number of changes in body and head position (per m) directed toward other flock members by individual grosbeaks as a function of group size and group geometry. Samples sizes for birds in circles for the listed groups sizes were 88, 75, 65, 67, 57, 73, and 63 . For birds in lines samples sizes were 88, 75, 54, 65, 47, 61, and 56. 
Fig. 3: Mean delays (s, +/- SD) in response to changes in group size by individual grosbeaks as a function of group size at the time that another bird departed or arrived and group geometry. Samples sizes for birds in circles for the listed groups sizes were 287, 250, 212, 183, 154, 137 , and 116. For birds in lines samples sizes were 287, 250, 187, 156, 133, 101, and 92.

Fig. 4: Point biserial correlations (r) for scanning among individual Evening Grosbeaks as a function of group size and group geometry. Samples sizes for birds in circles for the listed groups sizes were 218, 189, 163, 157, 161, and 132. For birds in lines samples sizes were 218, $189,186,137,116$, and 91. 